\title{
Improved treatment of early small hepatocellular carcinoma using sorafenib in combination with radiofrequency ablation
}

\author{
QUANYOU GONG ${ }^{1}$, ZHAOXIA QIN ${ }^{2}$ and FANGLI HOU ${ }^{1}$ \\ Departments of ${ }^{1}$ Intensive Care Unit and ${ }^{2}$ Urology, Zhumadian Central Hospital, Zhumadian, Henan 463000, P.R. China
}

Received August 1, 2016; Accepted March 24, 2017

DOI: 10.3892/ol.2017.7174

\begin{abstract}
Small hepatocellular carcinoma is an important leading cause of death amongst cancer patients, our study was designed in order to test the hypothesis that radiofrequency ablation (RFA) combined with a chemotherapeutic drug would improve the outcome for patients. Two groups of patients presenting early small hepatocellular carcinoma were treated with either conventional RFA alone (50 individuals in the control group), or with a combination of RFA and oral sorafenib (40 individuals in an observation group). Individual clinical and laboratory evaluations were done during an average follow-up time of 35 months, and all the data recorded was used to compare results of both treatment approaches. Tumor-free survival, relapse rate and survival rate, RFA interval and number of treatments, overall efficacy and the incidence of complications were analyzed. Serum levels of vascular endothelial growth factor (VEGF), connective tissue growth factor (CTGF), hypoxia inducible factor-1 $\alpha$ (HIF-1 $\alpha$ ) and osteopontin (OPN) were measured and compared. Our results show that the patients in the treatment group had statistically significant prolonged tumor-free survival, decreased relapse and increased survival rates. Also, the patients in the treatment group had significantly more prolonged average intervals of RFA and a lower number of treatments. Furthermore, the overall efficacy in the treatment group was increased, yet the incidence of complications was similar between both groups. Moreover, the serum levels of known tumorigenic factors VEGF, CTGF, HIF-1 $\alpha$ and OPN, which were similar between both groups before treatment, improved more markedly after the treatment in the observation group patients. Based on these findings, we propose that sorafenib in combination with percutaneous RFA is safe and efficacious, and a superior treatment for early small hepatocellular carcinoma. Larger studies are needed to corroborate our results.
\end{abstract}

Correspondence to: Dr Quanyou Gong, Department of Intensive Care Unit, Zhumadian Central Hospital, 747 Zhonghua West Road, Zhumadian, Henan 463000, P.R. China

E-mail: hvt72886848@163.com

Key words: sorafenib, percutaneous radiofrequency ablation, early small hepatocellular carcinoma, connective tissue growth factor, hypoxia inducible factor-1 $\alpha$, osteopontin

\section{Introduction}

Hepatocellular carcinoma is the fifth most frequent type of cancer in the global prevalence, and the third leading cause of cancer death. The Chinese prevalence of hepatocellular carcinoma accounts for 55\% of the global prevalence, and carcinoma ranks second amongst cancer mortality rates in China (1). Approximately $30-40 \%$ of patients with hepatocellular carcinoma get an early diagnosis with indications for surgical resection (2). The 5-year survival of advanced hepatocellular carcinoma is only $30-45 \%$ (3).

Sorafenib is an oral multi-kinase inhibitor for multiple signaling pathways. It can block the proliferation of tumor cells, inhibit angiogenesis and induce cell apoptosis, and has therefore been used against cancerous tissues (4). Several clinical studies have confirmed that sorafenib alone or in combination with other chemotherapies can prolong the survival in advanced hepatocellular carcinomas $(5,6)$.

Small hepatocellular carcinoma refers to a single lesion $<5 \mathrm{~cm}$ in diameter, or up to three lesions $<3 \mathrm{~cm}$ in diameter. Several studies have confirmed that radiofrequency ablation (RFA), percutaneous ethanol injection (PEI), microwave ablation, transcatheter arterial chemoembolization (TACE) and high intensity focused ultrasound (HIFU) have good safety and efficacy profiles in the treatment of early hepatocellular carcinoma $(7,8)$. These are important alternatives for whenever there are surgical contraindications due to an unsatisfactory tumor location, intolerance of surgical risk due to underlying conditions, or refusal of surgical treatment (9). This study further analyses the efficacy and short-term outcome of a therapy with sorafenib combined with RFA against early small hepatocellular carcinoma.

\section{Subjects and methods}

Subject information. The patients who were diagnosed for the first time, and pathologically confirmed as presenting a primary small hepatocellular carcinoma, were successively enrolled in this study. Patients excluded from the study had active viral hepatitis, severe cirrhosis, other liver diseases (such as fatty liver, alcoholic liver disease, autoimmune liver diseases); they could not complete required course of RFA and sorafenib therapy; or there was incomplete clinical information available for them. The Ethics Committee of Zhumadian Central Hospital approved the study and patients or their families 
Table I. Baseline information.

\begin{tabular}{lcccc}
\hline Group & Control group $(\mathrm{n}=50)$ & Treatment group $(\mathrm{n}=40)$ & $\mathrm{t} / \chi^{2}$ & P-value \\
\hline Male/female & $28 / 22$ & $23 / 17$ & 0.020 & 0.887 \\
Age (years) & $53.6 \pm 12.4$ & $55.7 \pm 13.6$ & 0.127 & 0.763 \\
Maximum tumor diameter $(\mathrm{cm})$ & $2.5 \pm 1.2$ & $2.6 \pm 1.4$ & 0.223 & 0.635 \\
No. of tumors & $1.5 \pm 0.5$ & $1.4 \pm 0.3$ & 0.152 & 0.732 \\
AFP $(\mu \mathrm{g} / \mathrm{l})$ & $562.4 \pm 56.7$ & $594.7 \pm 62.3$ & 0.327 & 0.649 \\
ALT $(\mathrm{U} / \mathrm{l})$ & $65.7 \pm 12.3$ & $64.8 \pm 13.5$ & 0.217 & 0.658 \\
Overall bilirubin $(\mu \mathrm{mol} / \mathrm{l})$ & $19.2 \pm 4.3$ & $21.3 \pm 4.5$ & 0.232 & 0.612 \\
Albumin $(\mathrm{g} / \mathrm{l})$ & $42.5 \pm 3.6$ & $41.7 \pm 3.8$ & 0.128 & 0.745 \\
\hline
\end{tabular}

AFP, alpha-fetoprotein; ALT, alanine aminotransferase.

signed written informed consents. A total of 50 cases of single RFA therapy (control group) and 40 cases of RFA combined with oral sorafenib (treatment group) participated. Table I lists the baseline information of the patients.

Methods. This study was performed by a single surgery and nursing team, which followed standard medical procedures. For RFA, the patient was in dorsal position under general anesthesia. The percutaneous puncture was guided by ultrasound (Aloka SSD-1100 Color Doppler Ultrasound; Siemens AG, Munich, Germany), Cool-tip RF system (Valleylab, Boulder, CO, USA), output frequency was $460 \mathrm{kHz}$, and maximum power $150 \mathrm{~W}$. Seven to twelve fine electrode needles were in the tip of a $14 \mathrm{G}$ trocar, a spherical thermocoagulation focus $(5.0 \mathrm{~cm})$ was formed after electrification. The actual power of RFA was $90 \mathrm{~W}$, the temperature was set at $100^{\circ} \mathrm{C}$, the ablation was terminated after achieving the preset temperature for $15 \mathrm{~min}$. After that, the ultrasound was used again to scan the ablation region. By modifying the location of the electrode needle, re-ablation could be performed based on the size of the tumor. The goal was to obtain high-echogenicity throughout the ablation region, which was $0.5-1 \mathrm{~cm}$ larger than the initial tumor lesion. After treatment, the unfolded electrode was taken out; the needle was withdrawn. The power of radio frequency was increased by $60 \mathrm{~W}$ in a stepwise manner to intensify the resistance. The treatment was done once the evaporation region of high echo covered the boundary of the tumor site. The needle was burnt after each withdrawal to prevent bleeding and metastasis. Contrast-enhanced abdominal CT was performed 1, 3, 6 and 12 months after treatment and then every 6 months after that. Re-ablation of new lesions was possible.

The patients in the combination therapy group were administrated sorafenib (registry no. H20130137; Bayer Pharma AG, Berlin, Germany) orally $400 \mathrm{mg}$, bid, for 4 weeks.

Observational measurements and detection methods. The median follow-up period was 35 months (6-50 months). Tumor-free survival, relapse and survival rates, RFA interval and number of treatments, overall efficacy and incidence of complications were all parameters evaluated. Additionally, serum levels of vascular endothelial growth factor (VEGF), connective tissue growth factor (CTGF), hypoxia inducible factor-1 $\alpha$ (HIF-1 $\alpha)$ and osteopontin (OPN) were measured.
Table II. Tumor-free survival, relapse and survival rate.

\begin{tabular}{lcccc}
\hline Groups & $\mathrm{N}$ & $\begin{array}{c}\text { Tumor-free } \\
\text { survival } \\
\text { (months) }\end{array}$ & $\begin{array}{c}\text { Relapse } \\
\text { rate, n (\%) }\end{array}$ & $\begin{array}{c}\text { Survival } \\
\text { rate, n (\%) }\end{array}$ \\
\hline Control & 50 & 8.4 & $17(34.0)$ & $35(70.0)$ \\
Treatment & 40 & 12.3 & $6(15.0)$ & $35(87.5)$ \\
$\chi^{2}$ & & 8.324 & 4.217 & 3.938 \\
P-value & & 0.006 & 0.040 & 0.047 \\
\hline
\end{tabular}

The efficacy of the treatment was evaluated according to the Response Evaluation Criteria In Solid Tumors (RESIST) scale, using the following formula: Overall efficacy $=(\mathrm{CR}+\mathrm{PR}+\mathrm{SD}) /$ overall number $\times 100 \%$, where $\mathrm{CR}$ is complete response, $\mathrm{PR}$ is partial response, $\mathrm{SD}$ is stable disease and PD is progressive disease. Peripheral venous blood $(6 \mathrm{ml})$ was collected. The samples were left to settle for $30 \mathrm{~min}$, before centrifugation at 3,000 $\mathrm{x}$ g for $20 \mathrm{~min}$. The supernatants were then isolated and stored at $-20^{\circ} \mathrm{C}$ for subsequent testing. The enzyme levels in the serum samples were determined using enzyme-linked immunosorbent assay (ELISA) tests according to the instructions in the kits used. All ELISA reagents were purchased from Sigma-Aldrich (St. Louis, MO, USA), and the microplate reader was purchased from Bio-Rad Laboratories, Inc. (Hercules, CA, USA).

Statistical analysis. SPSS 20.0 software (IBM, Armonk, NY, USA) was used for statistical analysis. Measurement data are presented by mean \pm standard deviation, inter-group differences were analyzed by independent sample t-tests, and intra-group differences by paired t-tests. Categorical data were analyzed by number or percentage (\%), and inter-group differences were analyzed by Chi-square tests. The survival rate was calculated using at Kaplan-Meier model and the log-rank Chi-square test. A P $<0.05$ was considered to indicate a statistically significant difference.

\section{Results}

Tumor-free survival, relapse and overall survival rates. The patients in treatment group had more prolonged tumor-free 
Table III. RFA interval and number of treatments.

\begin{tabular}{lcc}
\hline Groups & Mean interval (months) & No. of treatments \\
\hline Control & $3.6 \pm 0.8$ & $2.3 \pm 0.6$ \\
Treatment & $5.5 \pm 1.3$ & $1.9 \pm 0.5$ \\
t-test & 5.624 & 5.237 \\
P-value & 0.027 & 0.032 \\
\hline
\end{tabular}

RFA, radiofrequency ablation.

survival, lower relapse and longer survival rates; these differences compared to the patients in the control group were all significant $(\mathrm{P}<0.05)$ (Table II).

RFA interval and number of treatments. Compared to the control group, the patients in the treatment group had a significantly longer average interval of RFA and a decreased number of treatments $(\mathrm{P}<0.05)$ (Table III).

Overall efficacy and the incidence of complications. Also, when compared to the patients in the control group, those in the treatment group had a superior overall treatment efficacy; however, no differences were found between the groups in the incidence of complications (Table IV).

Serum levels of VEGF, CTGF, HIF-1 $\alpha$ and OPN. No significant differences were found between the average levels of serum VEGF, CTGF, HIF-1 $\alpha$ and OPN between treatment and control groups before treatment, $\mathrm{P}>0.05$. After treatment, however, all the levels in both treatment group and control group were lower, but significantly more so in the treatment group, $\mathrm{P}<0.05$.

\section{Discussion}

RFA can achieve complete necrosis of tumor tissues in a target region, with only limited injury of surrounding tissues. As a result, RFA has been extensively applied in early and moderately advanced hepatocellular carcinoma. Advantages such as the small wound it leaves, its convenience and applicability, the small probability of complications, and the requirement for only a short hospitalization period make this method a common one (10). Relapse after treatment is the major factor affecting long-term survival (11). RFA focuses on imagingvisible lesions, thus residual tiny lesions or satellite lesions may cause relapse (12). In addition, there are other factors that may affect the efficacy of RFA, such as the shape and distribution of the tumor, the ablation range and radiofrequency conditions (13).

Sorafenib is a targeting drug; it can inhibit tumor growth through inhibiting the activation of MAPK, JAK and Wnt signaling pathways (14). Sorafenib can also inhibit the activity of tyrosine receptors, which are closely associated with tumor growth and progress, including VEGF receptor 2, VEGF receptor 3, platelet-derived growth factor receptor 2 and c2KIT proto-oncogene. Sorafenib has been shown to block neovascularization in tumors and inhibit tumor growth

Table IV. Overall efficacy and incidence of complications, n (\%).

\begin{tabular}{|c|c|c|c|c|c|c|c|c|c|c|c|c|c|c|}
\hline Groups & $\mathrm{n}$ & CR & PR & SD & PD & $\begin{array}{l}\text { Overall } \\
\text { efficacy }\end{array}$ & Infection & Bleeding & Ascites & $\begin{array}{l}\text { Injury of } \\
\text { bile duct }\end{array}$ & $\begin{array}{l}\text { Liver } \\
\text { dysfunction }\end{array}$ & $\begin{array}{l}\text { Diarrhea or } \\
\text { constipation }\end{array}$ & $\begin{array}{l}\text { Hand-foot } \\
\text { reaction or } \\
\text { dental ulcer }\end{array}$ & $\begin{array}{c}\text { Total } \\
\text { incidence }\end{array}$ \\
\hline Control & 50 & 5 & 16 & 10 & 19 & $31(62.0)$ & 2 & 2 & 2 & 2 & 1 & 1 & 0 & $10(20.0)$ \\
\hline Treatment & 40 & 10 & 16 & 7 & 7 & $33(82.5)$ & 0 & 1 & 1 & 1 & 0 & 2 & 2 & 7 (17.5) \\
\hline$\chi^{2}$ & & & & & & 4.546 & & & & & & & & 0.091 \\
\hline P-value & & & & & & 0.033 & & & & & & & & 0.763 \\
\hline
\end{tabular}

CR, complete response; $\mathrm{PR}$, partial response; $\mathrm{SD}$, stable disease; $\mathrm{PD}$, progressive disease.

Table V. Serum levels of VEGF, CTGF, HIF-1 $\alpha$ and OPN.

\begin{tabular}{|c|c|c|c|c|c|c|c|c|}
\hline \multirow[b]{2}{*}{ Groups } & \multicolumn{2}{|c|}{ VEGF (pg/ml) } & \multicolumn{2}{|c|}{ CTGF (pg/ml) } & \multicolumn{2}{|c|}{$\mathrm{HIF}-1 \alpha(\mathrm{pg} / \mathrm{ml})$} & \multicolumn{2}{|c|}{ OPN $(\mu \mathrm{g} / \mathrm{l})$} \\
\hline & $\begin{array}{l}\text { Before } \\
\text { treatment }\end{array}$ & To follow-up & $\begin{array}{c}\text { Before } \\
\text { treatment }\end{array}$ & To follow-up & $\begin{array}{c}\text { Before } \\
\text { treatment }\end{array}$ & To follow-up & $\begin{array}{c}\text { Before } \\
\text { treatment }\end{array}$ & To follow-up \\
\hline Control & $567.4 \pm 65.7$ & $256.7 \pm 34.5$ & $765.8 \pm 86.5$ & $465.9 \pm 55.3$ & $254.3 \pm 56.4$ & $156.2 \pm 23.7$ & $153.2 \pm 23.6$ & $67.8 \pm 21.3$ \\
\hline Treatment & $584.9 \pm 58.3$ & $426.3 \pm 46.7$ & $774.2 \pm 92.3$ & $623.5 \pm 76.4$ & $276.5 \pm 58.9$ & $224.3 \pm 45.6$ & $167.4 \pm 32.4$ & $132.4 \pm 24.5$ \\
\hline t-test & 0.125 & 6.527 & 0.163 & 6.238 & 0.213 & 5.968 & 0.185 & 5.754 \\
\hline P-value & 0.862 & 0.012 & 0.824 & 0.016 & 0.742 & 0.020 & 0.768 & 0.023 \\
\hline
\end{tabular}

VEGF, vascular endothelial growth factor; CTGF, connective tissue growth factor; HIF-1 $\alpha$, hypoxia inducible factor-1 $\alpha$; OPN, osteopontin. 
indirectly (15). Moreover, sorafenib can induce tumor cell apoptosis or necrosis and increased autophagy (16). Currently, the efficacy of sorafenib for the treatment of advanced hepatocellular carcinoma, renal, colorectal, breast and cervical cancers is satisfactory (17).

Whether active chemotherapy should be used after surgery for early small hepatocellular carcinoma is still a controversial question, but most investigators support the notion that chemotherapy can further decrease the tumor relapse rate (18). This study used sorafenib in combination with RFA to treat early small hepatocellular carcinoma, with results that argue for the superiority of this approach. In the observation group, the tumor-free survival was prolonged (12.3 months), the relapse rate decreased $(15.0 \%)$, the survival rate increased $(87.5 \%)$, the mean interval of RFA prolonged, and the number of required treatments decreased, the overall efficacy increased $(82.5 \%)$, and the incidence of complications (17.5\%) was similar to that in the control group. Our results indicate that sorafenib in combination with RFA is safe and efficacious in the treatment of early small hepatocellular carcinoma. In comparison with a previous study of surgery alone, the survival rate was increased and the relapse rate was decreased (19). Importantly, after treatment, the serum levels of known pro-tumorigenic factors VEGF, CTGF, HIF-1 $\alpha$ and OPN in treatment group were significantly lower than those in the control group, $\mathrm{P}<0.05$. VEGF is an angiogenic factor in many malignancies, and the level of VEGF is closely related to the staging of TNM, clinical efficacy, survival and the prognosis (20). CTGF secreted by tumor cells can promote the synthesis of DNA and proliferation of tumor cells (21). HIF-1 $\alpha$ is involved in the metabolism, growth and metastasis of tumor cells, can increase the blood supply and oxygen utilization coefficient, and further improve the adaptability of tumor cells to hypoxic microenvironments (22). OPN is a bio-marker of hypoxia in tumor tissue, it can promote apoptosis and necrosis of tumor cells (23).

In conclusion, sorafenib in combination with percutaneous RFA is safe and effective in the treatment of early small hepatocellular carcinoma; this treatment can decrease serum levels of active tumor growth factors VEGF, CTGF, HIF-1 $\alpha$ and OPN, and is thus worthy of consideration. That said, the small sample size of our study and short follow-up period, call for larger studies for further validation.

\section{References}

1. Yung KW, Yung TT, Chung CY, Tong GT, Liu Y, Henderson J, Welbeck D and Oseni S: Principles of cancer staging. Asian Pac J Surg Oncol 1: 1-16, 2015.

2. Zheng YF, Tan LK, Tan BH, Sterling H and Kane R: Principles of surgical oncology. Asian Pac J Surg Oncol 1: 17-26, 2015.

3. Dobson PR, Brown BL, Beck D, Yang H, Zhou J and Voon YL: Management of surgical oncologic emergencies. Asian Pac J Surg Oncol 1: 59-72, 2015

4. Li WW, Dai ZY, Wan HG, Yao LZ, Zhu J, Li CL, Wang XJ, Pan J and Chen LZ: Endovascular implantation of iodine-125 seeds strand and portal vein stenting followed by transcatheter arterial chemoembolization combined therapy with sorafenib for hepatocellular carcinoma with main portal vein tumor thrombus. Zhonghua Yi Xue Za Zhi 96: 1838-1842, 2016 (In Chinese).

5. Dinh VY, Bhatia S, Narayanan G, Yrizarry J, Savaraj N, O'Brien C, Martin P and Feun L: Pilot study of intrahepatic artery chemotherapy in combination with sorafenib in hepatocellular carcinoma. Anticancer Res 36: 3555-3563, 2016.
6. Hatooka M, Kawaoka T, Aikata H, Morio K, Kobayashi T, Hiramatsu A, Imamura M, Kawakami Y, Murakami E, Waki K, et al: Comparison of outcome of hepatic arterial infusion chemotherapy and sorafenib in patients with hepatocellular carcinoma refractory to transcatheter arterial chemoembolization. Anticancer Res 36: 3523-3529, 2016.

7. Cahill T, Chen XL, Lee JW, Weiss M, Chang VT and Cella D: Principles of radiofrequency ablation for cancer. Asian Pac J Surg Oncol 1: 47-58, 2015.

8. Ghoneum M, Felo N, Nwaogu OM, Fayanju IY, Jeffe JA and Margenthaler DB: Clinical trials in surgical oncology. Asian Pac J Surg Oncol 1: 73-82, 2015.

9. Sterling B, Cole R, Jen KK and Shieh JS: Surgical oncology in the elderly. Asian Pac J Surg Oncol 1: 83-100, 2015.

10. Mellotte G, Maher V, Devitt PG, Shin VY and Leung CP: Minimally invasive surgical oncology: state of the art. Asian Pac J Surg Oncol 1: 101-112, 2015.

11. Sheta E, El-Kalla F, El-Gharib M, Kobtan A, Elhendawy M, Abd-Elsalam S, Mansour L and Amer I: Comparison of single-session transarterial chemoembolization combined with microwave ablation or radiofrequency ablation in the treatment of hepatocellular carcinoma: a randomized-controlled study. Eur J Gastroenterol Hepatol 28: 1198-1203, 2016.

12. Fujiwara H, Arai Y, Ishii H and Kanazawa S: Computed tomography-guided radiofrequency ablation for sub-diaphragm hepatocellular carcinoma: safety and efficacy of inducing an artificial pneumothorax. Acta Med Okayama 70: 189-195, 2016.

13. Sohn W, Kang TW, Choi SK, Jung SH, Lee MW, Lim HK, Cho JY, Shim SG, Sinn DH, Gwak GY, et al: Effect of oral antiviral treatment on long-term outcomes of radiofrequency ablation therapy for hepatitis B virus-related hepatocellular carcinoma. Oncotarget 14: 17-18, 2016.

14. Borentain P, Gregoire E, Louis G and Gerolami R: Successful liver transplantation for hepatocellular carcinoma following down-staging using sorafenib single therapy. Liver Int 36: 1393, 2016.

15. Shiozawa K, Watanabe M, Ikehara T, Kogame M, Kikuchi Y, Igarashi Y and Sumino Y: Therapeutic evaluation of sorafenib for hepatocellular carcinoma using contrast-enhanced ultrasonography: preliminary result. Oncol Lett 12: 579-584, 2016.

16. Xia F, Wu LL, Lau WY, Huan HB, Wen XD, Ma KS, Li XW and Bie P: Adjuvant sorafenib after heptectomy for Barcelona Clinic Liver Cancer-stage $\mathrm{C}$ hepatocellular carcinoma patients. World J Gastroenterol 22: 5384-5392, 2016

17. Zeng J, Lv L and Mei ZC: Efficacy and safety of transarterial chemoembolization plus sorafenib for early or intermediate stage hepatocellular carcinoma: a systematic review and meta-analysis of randomized controlled trials. Clin Res Hepatol Gastroenterol 20: 18-19, 2016.

18. Ishikawa T, Kubota T, Abe S, Watanabe Y, Sugano T, Inoue R, Iwanaga A, Seki K, Honma T and Yoshida T: Hepatic arterial infusion chemotherapy with cisplatin before radical local treatment of early hepatocellular carcinoma (JIS score 0/1) improves survival. Ann Oncol 25: 1379-1384, 2014.

19. Guo W, He X, Li Z and Li Y: Combination of transarterial chemoembolization (TACE) and radiofrequency ablation (RFA) vs. surgical resection (SR) on survival outcome of early hepatocellular carcinoma: a meta-analysis. Hepatogastroenterology 62: 710-714, 2015.

20. Zhu AX, Kang YK, Rosmorduc O, Evans TR, Santoro A, Ross P, Gane E, Vogel A, Jeffers M, Meinhardt G, et al: Biomarker analyses of clinical outcomes in patients with advanced hepatocellular carcinoma treated with sorafenib with or without erlotinib in the SEARCH trial. Clin Cancer Res 24: 182-183, 2016.

21. Lamarca A, Mendiola M, Bernal E, Heredia V, Díaz E, Miguel M, Pastrian LG, Burgos E, Feliu J and Barriuso J: Tumoural expression of connective tissue growth factor (CTGF) impacts on survival in patients diagnosed with hepatocellular carcinoma (HCC). Curr Cancer Drug Targets 15: 435-444, 2015.

22. Ma L, Li G, Zhu H, Dong X, Zhao D, Jiang X, Li J, Qiao H, Ni S and Sun X: 2-Methoxyestradiol synergizes with sorafenib to suppress hepatocellular carcinoma by simultaneously dysregulating hypoxia-inducible factor- 1 and -2 . Cancer Lett 355: 96-105, 2014.

23. Dong Q, Zhu X, Dai C, Zhang X, Gao X, Wei J, Sheng Y, Zheng Y, Yu J, Xie L, et al: Osteopontin promotes epithelial-mesenchymal transition of hepatocellular carcinoma through regulating vimentin. Oncotarget 7: 12997-13012, 2016. 